\title{
RESERVOIR SYSTEMS OPERATION MODEL USING SIMULATION AND NEURAL NETWORK
}

\author{
Jianxia Chang ${ }^{1,2}$ Yimin Wang ${ }^{1}$ Qiang Huang ${ }^{1}$ \\ 1 Xi'an University of Technology, 2 Xi' an University of Architecture and Technology, Shaan \\ $x i, X i^{\prime}$ an, 710048
}

Abstract: For multi-reservoir operating rules, a simulation-based neural network model is developed in this study. In the suggested model, multi-reservoir operating rules are derived using a neural network from the results of simulation. The training of the neural network is done using a supervised learning approach with the back propagation algorithm. The Yellow River upstream multireservoir system is used for this study. This paper presents the usefulness of the neural network in deriving general operating policies for a multi-reservoir system.

Key words: reservoir operating rules, simulation model, neural network, the Yellow River

\section{LITERATURE REVIEW}

Simulation models for reservoir operation studies generally permit detailed and realistic representation of the complex characteristics of a reservoir system. The concepts are easier to understand and communicate than other modeling concepts. The first publications documenting research in developing reservoir system simulation were produced by the Harvard Water Porgram (Maass et al. 1962). Examples of current state of the art include HEC-3 and HEC-5 models developed by the Hydrologic Engineering Center and described by Feldman(1981).

Application of artificial neural networks in water resources system analysis is fast growing. An artificial neural network is a model inspired by 
the structure of the brain that is well suited for complicated tasks. Ranjithan et al. (1993) used neural networks as screening models for a groundwater reclamation problem. Karunanithi et al. (1994) used neural networks for flow predictions. Zhang \& Govindaraju (2000) used a modular neural network for a watershed runoff model. Different modules within the network were trained to learn subsets of the input space in an expert fashion. Chandramouli \& Raman (2001) developed a multi-reservoir operation model using dynamic programming and a neural network. They used a three state variable dynamic programming algorithm in a constrained manner. In that dynamic programming model the three releases from the reservoirs considered were the decision variables.

In this study, a backpropagation neural network model is trained to derive reservoirs operation rules. To train the neural network, exemplars are required and obtained through a simulation model.

\section{SYSTEM CONSIDERED}

The system considered for the case study is the Yellow River upstream project in China. This is a multipurpose, multireservoir project. Operation of this system is monitored by the Yellow River Conservancy Commission. The system consists of three reservoirs, Long yangxia reservoir, Li jiaxia reservoir and Liu jiaxia reservoir, as given in Table 1. Among these reservoirs, Longyangxia is a yearly regulation reservoir, Li jiaxia is runoff reservoir, and Liu jiaxia is a annual regulation reservoir. The objectives for reservoir operation of this system include municipal, industrial, irrigation water supply, power generation and ecological purposes.

Table 1. Reservoir system characteristics

\begin{tabular}{llllll} 
Reservoir & $\begin{array}{l}\text { Inflow } \\
\left(\mathrm{m}^{3} / \mathrm{s} \text { year }\right)\end{array}$ & $\begin{array}{l}\text { Total } \\
\text { Storage } \\
\left(10^{9} \mathrm{~m}^{3}\right)\end{array}$ & $\begin{array}{l}\text { Normal } \\
\text { Reservoir } \\
\text { Level }(\mathrm{m})\end{array}$ & $\begin{array}{l}\text { Flood } \\
\text { Control } \\
\text { Level }(\mathrm{m})\end{array}$ & $\begin{array}{l}\text { Power Plant } \\
\text { Capacity } \\
\left(10^{3} \mathrm{~kW}\right)\end{array}$ \\
\hline Longyangxia & 650 & 24.7 & 2600 & 2594 & 1280 \\
Li jiaxia & 664 & 1.65 & 2180 & & 2000 \\
Liujiaxia & 877 & 5.7 & 1735 & 1726 & 1160 \\
\hline
\end{tabular}

\section{SIMULATION MODEL}

The simulation model of a reservoir system is based on water balance of reservoirs. Figure. 1 is a schematic representation of a reservoir system. For reservoir $i$ in period $t$, the water balance can be written as: 
Network

$$
V_{i, t}=V_{i, t-1}+I_{i, t}-P_{i, t}-W_{i, t}-G_{i, t}-E V_{i, t}+\sum_{k=1}^{m} A_{i, k} D_{k, t}
$$

where $\mathrm{V}_{i, t}$ - the storage level of reservoir $i$ at the end of period $t, I_{i, t}$ random inflow into reservoir $i$ during period $t, P_{i, t}$ - water release through power plant from reservoir $i$ during period $t, W_{i, t}$ - water release for water supply from reservoir $i$ during period $t, G_{i, t}$ - release to maintain the maximum allowable storage in reservoir $i$ during period $t, E V_{i, t}$ - evaporation from reservoir $i$ during period $t, D_{i, t}$ - downstream flow from reservoir $i$ during period $t, A_{i, k}=1$ if reservoir $k$ releases flows into reservoir $i$, and 0 otherwise, $m$ - number of reservoirs in the system.

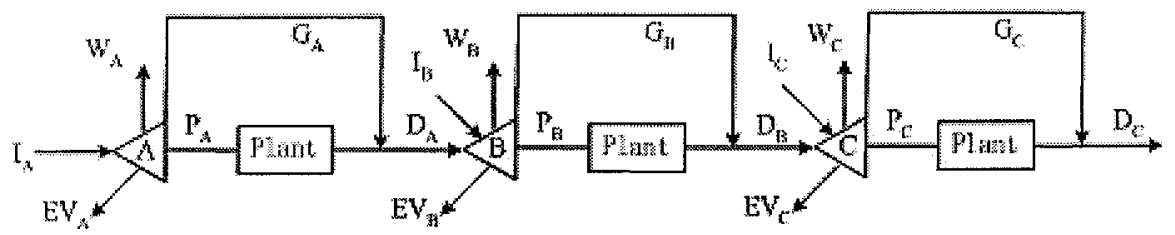

Figure 1. Schematic representation of a reservoir system

On the basis of equation (1), operation statuses can be simulated for each reservoir. In the case study, A denotes reservoir Long yangxia, B denotes reservoir $\mathrm{Li}$ jiaxia, and $\mathrm{C}$ denotes reservoir Liu jiaxia.

\subsection{Simulation Constraints}

The model constraints includes:

(1) water balance between reservoirs

Some factors such as the time of flow transmitting, water diversion, water loss, returning water, and inflow between up reservoir and down reservoir are considered in the water balance equation.

$$
Q_{\text {down }, t}=Q_{\text {up }, t-1} \times \frac{t}{T}+Q_{\text {up }, t} \times \frac{(T-t)}{T}+q_{\text {add }, t}+q_{\text {returnt },}-q_{\text {diver, }, t}-q_{\text {lass }, t}
$$

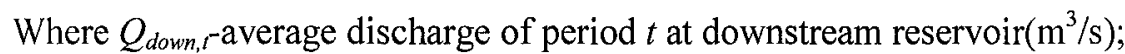
$Q_{u p, t}, Q_{u p, t-1}$-average discharge of period $t$ and $t-1$ at upstream reservoir $\left(\mathrm{m}^{3} / \mathrm{s}\right)$; $t$ - time of water transmission from upstream to downstream reservoir(day); $\mathrm{T}$ - number of days in the month(day); $q_{\text {add, }, t}, q_{\text {retur }, l}, q_{\text {diver }, t}, q_{\text {loss }, t}$-average inflow, return, divert, and water loss between upstream and downstream reservoir $\left(\mathrm{m}^{3} / \mathrm{s}\right)$.

(2) reservoir water balance

$$
V(m, t+1)=V(m, t)+(Q R u(m, t)-Q R c(m, t)) \times \Delta T(t)-L W(m, t)
$$


Where m-reservoir number, $m=1$ denote Longy angxia, $m=2$ denote $\mathrm{Li}$ jiaxia, $m=3$ denote Liu jiaxia; $V(m, t+1), V(m, t)$ - the reservoir storage of number $m$ at the end and begin of period $t ; Q R u(m, t), Q R c(m, t), L W(m, t)$ - the inflow, outflow and water loss of number $m$ reservoir during the period $t$.

(3) other constraints

$$
\begin{gathered}
V \min (m, t) \leq V(m, t) \leq V \max (m, t) \\
q \min (m, t) \leq Q R c(m, t) \leq q \max (m, t) \\
N \min (m, t) \leq N(m, t) \leq N \max (m, t)
\end{gathered}
$$

Where $N(m, t)$ - the reservoir output of number $m$ during period $t$; $\operatorname{Vmin}(m, t), V \max (m, t)$ - the minimum and maximum reservoir storage values in time $t ; q \min (m, t)$, qmax $(m, t)$ - the minimum and maximum reservoir discharge in time $t ; \operatorname{Nmin}(m, t), \operatorname{Nmax}(m, t)$ - the minimum and maximum output values in time $t$.

(4) ice-jam prevention constraint

Ice prevention requires certain discharge from Liujiaxia reservoir, and the discharge inversion is used in computation, i.e. the flow requirement is computed from Lanzhou to Liujiaxia.

\subsection{Simulation Principle}

The principle of simulation model operation is as follows:

1. The priority order for water supply is, ecological, municipal and industrial, agricultural, and power generation requirement.

2. The reservoir storage must satisfy the requirement of flood control and ice-jam prevention. Ice-jam occurred in Lanzhouin in the period of November till next March, thus the discharge from Liujiaxia reservoir must comply with the flood control limitation in the November till next March.

3. The water demand from Liujiaxia is satisfied by the joint operation of Longyangxia and Liujiaxia reservoir.

4. In terms of historical data statistics, the water transmission period in channel is considered.

During the simulation procedure, extensive knowledge and experiences of operators are required to set constraint limits, such as the ice-jam control flow and ecological base flow etc. while using the simulation model, the operator first interactively determines the constraint limits, and then alternative for reservoir operation can be acquired automatically. 


\subsection{Simulation Results}

For the considered system, 49 years of flow records from 1951 to 1999 are available, and computation time period is month. The operation results for typical dry year 1970-1971 are shown in Table 2.

Table 2. Operation Results for typical dry year

\begin{tabular}{|c|c|c|c|c|c|c|c|c|}
\hline \multirow[b]{2}{*}{ month } & \multicolumn{4}{|c|}{ Long yangxia } & \multicolumn{4}{|c|}{ Liu jiaxia } \\
\hline & $\begin{array}{l}\text { Inflow } \\
\left(\mathrm{m}^{3} / \mathrm{s}\right)\end{array}$ & $\begin{array}{l}\text { Release } \\
\text { Flow } \\
\left(\mathrm{m}^{3} / \mathrm{s}\right)\end{array}$ & $\begin{array}{l}\text { Reservoir } \\
\text { Level } \\
\text { (m) }\end{array}$ & $\begin{array}{l}\text { Power } \\
\text { Output } \\
\left(10^{4} \mathrm{~kW}\right)\end{array}$ & $\begin{array}{l}\text { Inflow } \\
\left(\mathrm{m}^{3} / \mathrm{s}\right)\end{array}$ & $\begin{array}{l}\text { Release } \\
\text { Flow } \\
\left(\mathrm{m}^{3} / \mathrm{s}\right)\end{array}$ & $\begin{array}{l}\text { Reservoir } \\
\text { Level } \\
\text { (m) }\end{array}$ & $\begin{array}{l}\text { Power } \\
\text { Output } \\
\left(10^{4} \mathrm{~kW}\right)\end{array}$ \\
\hline 7 & 727 & 526 & 2588.7 & 59.1 & 715 & 1065 & 32.0 & 90.6 \\
\hline 8 & 1180 & 513 & 2593.6 & 59.0 & 953 & 863 & 34.3 & 71.5 \\
\hline 9 & 569 & 503 & 2594.1 & 59.0 & 944 & 731 & 40.0 & 62.9 \\
\hline 10 & 614 & 504 & 2594.8 & 59.4 & 798 & 652 & 43.8 & 58.3 \\
\hline 11 & 349 & 502 & 2593.7 & 59.0 & 630 & 646 & 43.4 & 58.2 \\
\hline 12 & 177 & 511 & 2591.4 & 59.4 & 574 & 650 & 41.4 & 58.3 \\
\hline 1 & 139 & 517 & 2588.5 & 59.0 & 588 & 660 & 39.5 & 58.4 \\
\hline 2 & 135 & 532 & 2585.5 & 59.4 & 611 & 669 & 38.0 & 58.4 \\
\hline 3 & 201 & 545 & 2582.8 & 59.5 & 603 & 446 & 42.1 & 39.6 \\
\hline 4 & 336 & 545 & 2581.2 & 58.5 & 584 & 656 & 40.2 & 58.3 \\
\hline 5 & 487 & 554 & 2580.7 & 58.9 & 632 & 661 & 39.5 & 58.2 \\
\hline 6 & 639 & 558 & 2581.3 & 59.4 & 623 & 1252 & 22.9 & 101.6 \\
\hline
\end{tabular}

\section{NEURAL NETWORK FOR CONSIDERED SYSTEM}

\subsection{Neural Networks (NN)}

NN performs two major functions, learning and recall. Learning is the process of adapting the connection weights or structure in an NN to produce the desired output in response to a stimulus presented to the input buffer. Recall is the process of accepting an input stimulus and producing an output response in accordance with the network weight structure. The backpropagation learning algorithm (BPL) is among the well-known algorithms used to train a given neural network. This learning algorithm is applied to multilayer feed-forward network consisting of processing neurons with differentiable activation functions. For a given input-output pair $\left(x_{k}, d_{k}\right)$, the BPL performs two phases of data flow. First, the input pattern $x_{k}$ is propagated from the input layer to the output layer and, as a result of this 
forward flow of data, it produces the actual output $y_{k}$. The error signals, resulting from the difference between the target output $d_{k}$ and the actual output $y_{k}$, are then back-propagated from the output layer to the previous layers to update their weights.

The procedure for training the network is embodied in the following steps:

1. Apply an input vector to the network and calculate the corresponding output values;

2. Compare the outputs from the model with the target outputs and determine a measure of the errors;

3. Determine to increase or decrease the weights or find in which direction to change each weight in order to reduce the error;

4. Determine the amount by which to change each weight;

5. Apply the corrections to the weights;

6. Repeat items 1 to 5 with all the training vectors until the error for all vectors in the training set is reduced to an acceptable value.

In order to obtain the operating policy of the Yellow River upstream reservoirs system, a neural network is designed, which has three layers. The input and output patterns are derived from simulation results. The neural network considered has eight input nodes and three output nodes. Figure. 2 shows the proposed neural network. Release from reservoirs Long yangxia, Li jiaxia and Liu jiaxia during time period $t$ are the outputs from the neural network. During time period $t$, initial storage of reservoir Long yangxia, inflow into reservoir Long yangxia, demand from reservoir Long yangxia, inflow into reservoir $\mathrm{Li}$ jiaxia, demand from reservoir $\mathrm{Li}$ jiaxia, initial storage of reservoir Liu jiaxia, inflow into reservoir Liu jiaxia, demand from reservoir Liu jiaxia are input patterns. The input patterns are decided by considering the variables that are influencing the reservoirs release. These dates are given to the neural network module for training. The neural network is trained with these patterns using back-propagation algorithm to derive the operating rules.

\subsection{Measure of Errors}

Square error (MSE) and relative error (MRE) are used for deciding the best network. MSE and MRE are defined as follows:

$$
\begin{aligned}
M S E & =\frac{1}{2} \sum_{q} \sum_{j=1}^{p}\left(y_{j}^{\prime}-y_{j}\right)^{2} \\
M R E & =\frac{1}{p q} \sum_{q} \sum_{j=1}^{p}\left|\frac{y_{j}^{\prime}-y_{j}}{y_{j}^{\prime}}\right| \times 100
\end{aligned}
$$




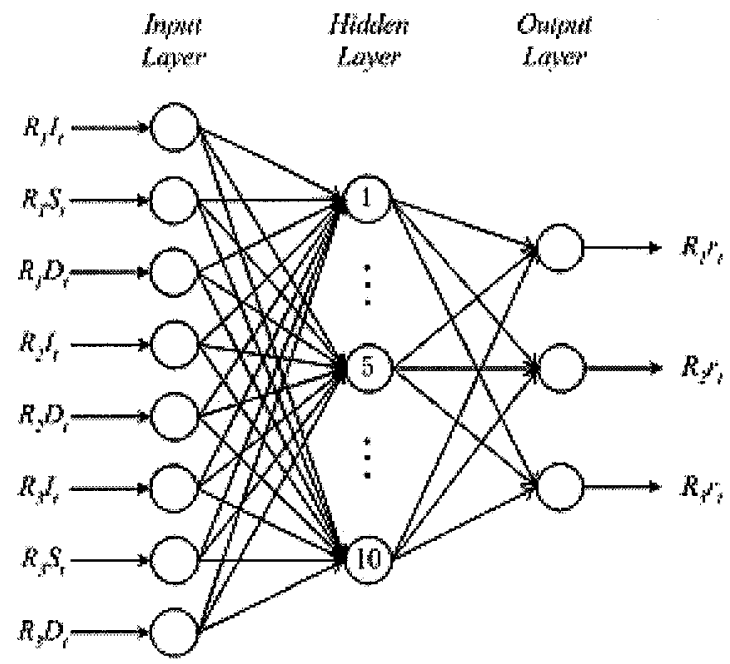

Figure 2. Neural network model for considered system

where $p$-number of patterns used for training; $q$-number of nodes in the output layer; $y_{j}{ }^{\prime}$-target output pattern value; and $y_{j}$-output from neural network model. The MSE value indicates the goodness of fit at high output values and MRE value indicate the goodness of fit for moderate output values.

\subsection{Backpropagation Network Performance}

The two strategies adopted for testing the applicability of the neural network in the present work are (1) to test the capability of the neural network to correctly predict the output for the given input set originally used to train the network (accuracy performance); and (2) to test the capability of the neural network to correctly predict the output for the given input sets that were not in the training set (generalization performance).

The network architecture, learning rate $\eta$, and momentum factor $\alpha$ values were adjusted to speed up the convergence. In this study, only one hidden layer was used in all the cases. The optimal architecture considered has 10 neurons in the hidden layer. The trial for this study is started with 2 neurons in the hidden layer and the network is studied up to a model with 14 neurons in the hidden layer. The architecture with 9 nodes in the hidden layer was faster in computation, but the convergence was very slow. The architecture with 11 nodes in the hidden layer was converging equally well as with 10 nodes in the hidden layer but relatively slower than that. So the architecture with 10 nodes in the hidden layer was selected. Learning rate $\eta$, which is the 
step size of the steepest gradient descent algorithm, is taken as 0.7 . If it is too high, the search may miss a valley in the error surface. On the other hand, if it is too small, the convergence will be very slow. The $\alpha$ value for this study is kept at 0.5 . Since sigmoidal function is used in the output layer, the output value form the network lies between 0 and 1 . Hence normalization of the data is essential. Input patterns are normalized based on MSE and MRE values for the given data set. The interconnecting weights are initialized by random numbers between -1 and 1 . The weights are re-adjusted while training using the back propagation algorithm for the supplied patterns.

\section{CONCLUSION}

An important notion tested in this research was that artificial NN have a potential to mimic, to a large extent, the high level information processing performed by human operators. This paper presents the usefulness of the neural network in deriving operating policies for a multireservoir system. From simulation results, to derive general operating policies, NN can be used. Generating the examples requires the conventional simulation model, and the training process requires considerable time. The method suggested is a baseline and is flexible to adopt in many problems. These results indicate the ability of the NN to capture knowledge from more complex system.

\section{REFERENCE}

[1] Simonovic S. P.: Reservoir systems analysis: Closing gap between theory and practice. Journal of Water Resources Planning and Management, Vol. 118. (1992) 262-280

[2] Yeh W W-G.:Reservoir management and operations models: a state-of-the-art review. Journal of water Resources Research, Vol. 21. (1985) 1797-1818

[3] Wurbs R A.: Reservoir-system simulation and optimization models. Journal of Water Resources Planning and Management, Vol.119. (1993) 455-472

[4] HEC-5 simulation of flood control and conservation systems user's manual. (1982), U.S. Army Corps of Engineers, Hydrologic Engineering Center, Davis, Calif.

[5] Ranjithan, S., Eheart, J. W., and Grarrett, J. H.:Neural network based screening for groundwater reclamation uncertainty. Journal of Water Resource Research, Vol.29. (1993)563-574

[6] Karunanithi, N., Grenney, W. J., Whitley, D., and Bovee, K.:Neural network for river flow prediction. J. Comp. in Cic. Engrg., ASCE, VOL.8. (1994) 201-220

[7] Zhang, B.,Govindaraju, R.S. : Prediction of watershed runoff using Bayesian concepts and modular neural networks, Journal of Water Resources Research, Vol. 36. (2000) $753-762$

[8] Chandramouli, V. \& Raman, H.: Multi reservoir modeling with dynamic programming and neural network. Journal of Water Resources Planning and Management, Vol.127. (2001) 89-98 